\title{
X-Ray Diffraction Analysis of Bitumen Containing Untreated and Treated Waste Cooking Oil
}

\author{
Wan Nur Aifa Wan Azahar, Ramadhansyah Putra Jaya, Mohd Rosli Hainin, Mohd Rosli Mohd \\ Hasan, Ekarizan Shaffie
}

\begin{abstract}
Abundant of waste cooking oil (WCO) production can cause prominent adverse impact and threat to the environment if not properly managed and disposed. Therefore, recycling or reusing WCO in modified asphalt binder is considered as an effective utilisation and environmental benefits. Hence, this study was to evaluate the chemical characteristic of untreated and treated WCO in modified binder through X-Ray diffraction analysis. The results indicated that the amorphous structure was present in the control and modified binders with untreated and treated WCO. The flat trends tabulated in XRD graph for modified binder depicted the uniform dispersion and homogeneous solution was achieved between the untreated and treated WCO with the asphalt binder during mixing process.
\end{abstract}

\section{Keywords: XRD, WCO, Bitumen, Untreated, Treated.}

\section{INTRODUCTION}

In recent years, a wide range of oil-based modifications have been introduced, especially involving waste cooking oil (WCO). The WCO is also recognised as waste grease oil which is characterised as the by-product of fresh cooking oil produced during cooking and food processing. This oil source has recently gained widespread attention because of its satisfactory achievement as a potential waste material to enhance the physical and rheological performance of modified binder. The oil undergoes three types of common chemical reaction during frying, such as hydrolysis, oxidation and polymerisation. The chemical process in oil causes degradation in the physical and chemical properties [1] which affects WCO quality. Physical properties include alteration in foaming quantity, colour, viscosity, density and flavour. Meanwhile chemical properties are represented as total unsaturation compound, free fatty acid content, polar and polymeric material. The generation of huge quantities of WCO is attributed by the increasing human population and its use as a frequent medium for food preparation involving frying. It can be noticed that WCO production quantity is directly proportional to frying rate.

Revised Manuscript Received on October 22, 2019

* Correspondence Author

Wan Nur Aifa Wan Azahar, Kulliyyah of Engineering, Department of Civil Engineering, International Islamic University Malaysia, Kuala Lumpur, Malaysia

Ramadhansyah Putra Jaya*, Faculty of Civil Engineering Technology, Universiti Malaysia Pahang, Gambang, Pahang, Malaysia

Mohd Rosli Hainin, Faculty of Civil Engineering Technology, Universiti Malaysia Pahang, Gambang, Pahang, Malaysia

Mohd Rosli Mohd Hasan, School of Civil Engineering, Engineering Campus, Universiti Sains Malaysia, Penang, Malaysia

Ekarizan Shaffie, Institute for Infrastructure Engineering and Sustainable Management (IIESM), Universiti Teknologi MARA, Selangor, Malaysia
According to Chhetri et al. [2], enormous quantity of WCO that is generated worldwide is illegally dumped and released into the surrounding environment. In Malaysia, the disposal of WCO is reported to be approximately around 50,000 tons, which was produced from plant and animal based fats source [3]. These wastes are disposed to the environment without undergoing any proper treatment [4]. A survey conducted by Kabir et al. [5] revealed that the majority of the respondents (54.5\%) discard WCO into their house sink. Meanwhile $22.2 \%$ stated that the WCO is dumped into drains. This coincides with the response on the level of awareness on WCO recycling. Unexpectedly, only $12 \%$ of the households WCO are recycled, while most of the respondents (about $88 \%$ ) did not practice waste recycling as they discharge WCO improperly. Such inappropriate action has consequently induced an undesirable impact to the entire environmental ecosystem, for instance distraction of aquatic life, contamination of water and soil, sewer system blockage and increased maintenance cost for water treatment and waste management [6].

Abundant of WCO production can cause prominent adverse impact and threat to the environment if not properly managed and disposed. Therefore, recycling or reusing WCO in modified asphalt binder is considered as an effective utilisation and management of this waste while at the same time ensuring economic and environmental benefits [7]. It is noteworthy that, most researchers have focused on the superior performance of $\mathrm{WCO}$ as a rejuvenator for aged binder $[8,9,10,11,12,13,14]$, apart from substituting WCO in modified binder to improve rheological performance. The WCO performance as a modifier at high and low temperatures was evaluated by Wen et al. [15]. The rheological findings indicate declination of the complex modulus $\left(\mathrm{G}^{*}\right)$, which resulted in a low rutting resistance at high temperature. On the contrary, an increment in thermal cracking resistance performance at low-temperature was observed to occur linearly with the addition of WCO content.

This rheological result coincides with the study conducted by Maharaj et al. [16] for un-aged sample, wherein an enhancement of fatigue cracking resistance was achieved at low temperature. Meanwhile, the high temperature performance showed an adverse effect as the rutting resistance decreased with the addition of WCO. This is also supported by Sun et al. [17], which reveals the decrement of deformation resistance and improvement of thermal cracking resistance performance when using the modified binder incorporated with bio-oil derived from WCO.

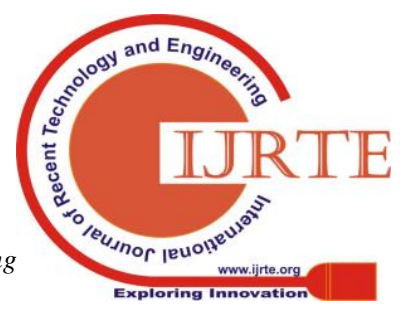


According to Teymourpour et al. [18], the application of WCO in conventional binder proved an enhancement of thermal cracking resistance but compromising the high temperature performance as evidenced by the reduction of resistance to rutting. The superiority performance of fatigue cracking resistance was noticeable with the addition of WCO as reported in a previous research. It proves that the capability of WCO to improve low temperature performance, while deteriorating the rutting resistance performance at high temperature.

The WCO in asphalt binder softens the physical properties of modified asphalt binder, thereby unable to withstand rutting exposure. According to Katamine [19], the negative indicator in the quality of bitumen is expected with the addition of WCO in bitumen. This serves as the major reason why WCO is not suggested for optimal utilisation, due to its poor performance in rutting resistance, which is not desirable especially for hot climatic region. Waste oil needs to be fully re-evaluated and assessed by undergoing further treatment before being recommended and applied in the asphalt binder to produce bituminous mixture [20].

However, despite the broadly practiced WCO application, the identification of fundamental parameters influencing WCO in binder modification and also the effectiveness of the process has not been investigated yet [18]. In addition, the chemical mechanism for modifying asphalt binder with WCO and the effect of WCO on the modified binder performance are not clearly documented. Obviously, the softer and less viscous modified binder with WCO depicts the weakness of internal chemical bonding of the material. Hence, there is the issue of chemical compatibility and interprets an assumption of incompatibility between these two materials due to chemical properties that should be further clarified and investigated.

\section{MATERIALS AND METHODS}

\section{A. Binder}

Asphalt binder with penetration grade of 60/70 was used as control bitumen. The asphalt binder source was supplied by Wira Bakti Solution Company and met all the requirements specified by the Malaysian Public Works Department standard.

\section{B. Untreated WCO and Treated WCO}

Basically, two types of modifier was added into control binder to produce modified binder which can be divided into untreated WCO and treated WCO as shown in Fig. 1. For untreated WCO, this modifier is recognized as fresh/raw WCO which was collected from food restaurant and mostly disposed without undergoing any proper treatment [4]. Meanwhile, treated WCO is derived from the untreated WCO wherein this modifier underwent chemical treatment through transesterification process. This chemical process is conducted when the untreated WCO is chemically reacted with methanol (alcohol) in the presence of sodium hydroxide $(\mathrm{NaOH})$ as base catalysts to produce treated WCO. Prior to the process, a total of $1 \mathrm{~mL} \mathrm{NaOH}$ and $600 \mathrm{~mL}$ of methanol were weighted and mixed together. Thereafter, this solution was added into $100 \mathrm{~mL}$ of untreated WCO in a beaker containing a magnetic stirring bar to ensure a homogeneous solution obtained during the reaction. The solution was heated on the hot plate until reached at a temperature of $65^{\circ} \mathrm{C}$ and the reaction was started for a duration time of $1 \mathrm{hr}$. The reaction was completed when the separation of two major by-products were observed namely, treated WCO at the upper phase and glycerol in the lower phase.

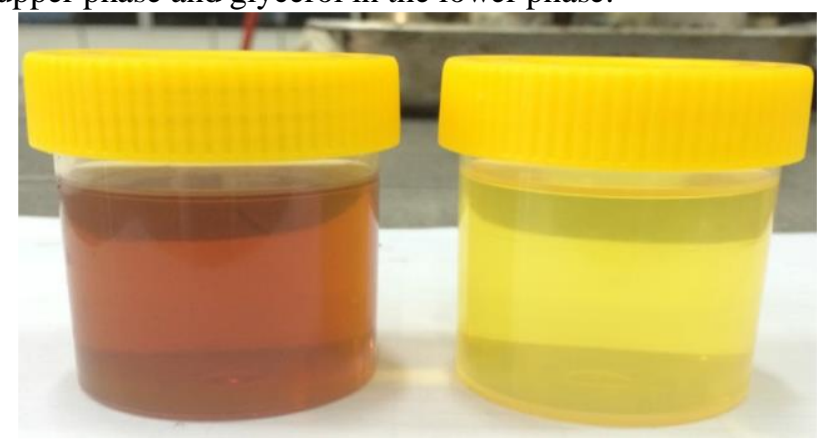

Fig. 1. Untreated WCO (left) and treated WCO (right)

\section{Modified Binder with Untreated and Treated WCO}

Modified binder was prepared when the $5 \%$ of untreated WCO and treated WCO was added and mixed into the 60/70 bitumen. This percentage was selected based on the optimum binder performance obtained from previous study [21]. At the laboratory, the materials were blended by using a high shear mixer at a constant speed of $1000 \mathrm{rpm}$ for $1 \mathrm{~h}$ at $160^{\circ} \mathrm{C}$.

\section{X-Ray Diffraction (XRD) Test}

The atomic arrangement and homogeneity of the sample mixture was determined by interpreting the graph pattern produced by X-Ray Diffraction (XRD), as shown in Fig. 2. Basically, the XRD is a non-destructive analytical technique for crystalline phase identification in the material. The diffraction pattern produced from the scattering of atom illustrates information on the atomic arrangement inside the material. The samples were scanned with a scan speed of $10.0619 \mathrm{deg} / \mathrm{min}$ in the specified diffraction angle in between $5^{\circ}-90^{\circ}$ degree in two-theta. Copper $(\mathrm{Cu}=\mathrm{k} \alpha)$ was used as the $\mathrm{X}$-ray source with a wavelength, $\lambda$ of 1.5406 at $40 \mathrm{kV}$ and $30 \mathrm{~mA}$.

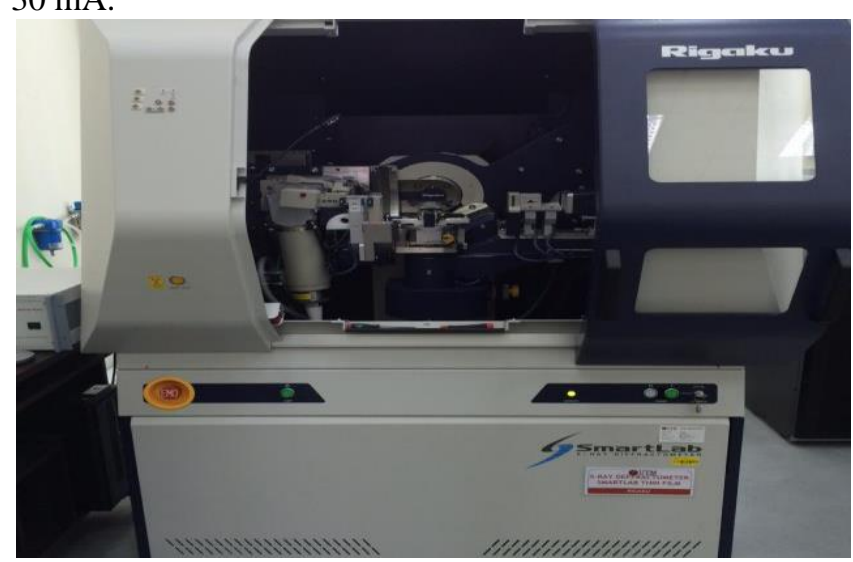

Fig. 2. XRD equipment

\section{RESULTS AND DISCUSSION}

\section{A. Control Binder}

The graph pattern of the control binder generated from the X-Ray Diffraction (XRD) is presented in Fig. 3. In the 
control binder sample, the graph pattern generated from this test interpreted data on the arrangement of atom inside the material. The diffraction pattern was affected by atomic arrangement in which the $\mathrm{X}$-ray was scattered when the atoms were arranged in periodic array. Based on the XRD graph, it can be noticed that the notable consistency of graph pattern, without the presence of large peak, was observed for the control binder sample. Only one small peak existed in the control binder sample which appeared at $19^{\circ} 2 \theta$ with $d=$ 4.48. Generally, the value of ' $d$ ' represented the peak width which indicated the crystallite size. The presence of peak indicated that the atom was arranged in the periodic array and was thereby recognised as the crystalline structure. However, this sample was not identified as an entirely crystallise structure since the existence of peak was not dominant and slightly lower in the control binder sample.

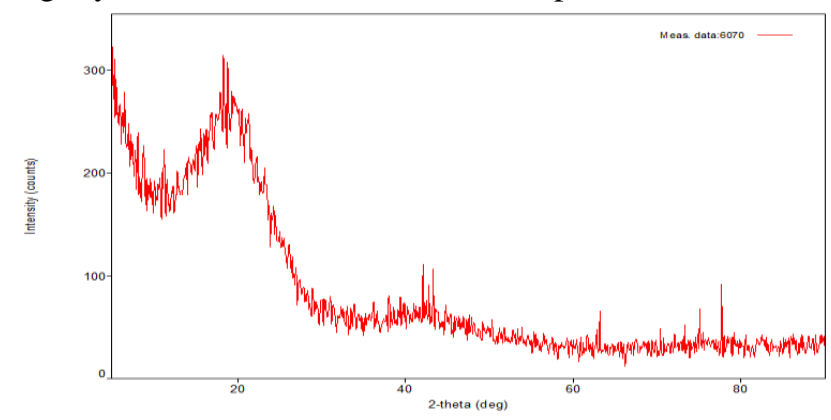

Fig. 3.

\section{B. Modified Binder with Untreated WCO}

Fig. 4 illustrates the trend of graph for the modified binder with untreated WCO, which was tabulated from the XRD test. In the modified binder sample, the graph pattern interpreted two types of data, which were the arrangement of atom inside the material and the homogeneity of untreated and treated WCO in modified asphalt binder. A similar graph pattern with control binder was observed in modified binder containing untreated $\mathrm{WCO}$, which was identified from the presence of only one notable peak. Based on the XRD graph, the peak existed at $18^{\circ} 2 \theta$ with the peak width recorded as $\mathrm{d}=$ 4.69. Similar with control binder, the modified binder with untreated WCO was not recognized as crystalline structure since this peak was presented as a minor component in the graph. On the contrary, a noticeable quite flat pattern graph was observed which was presented for the whole graph in this sample.

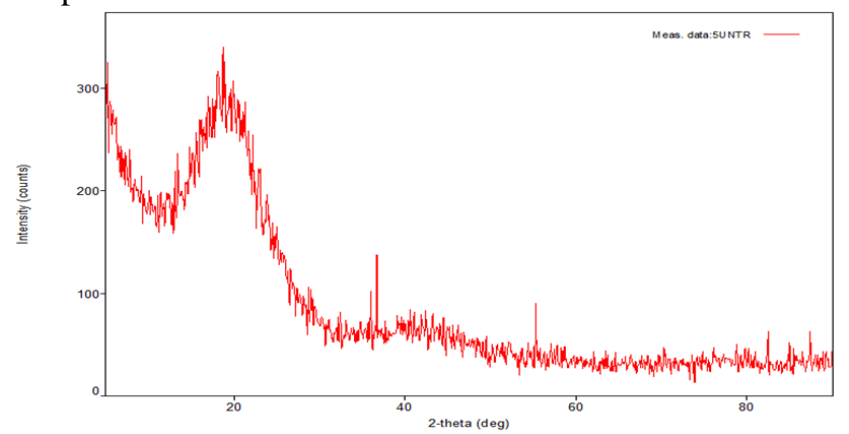

Fig. 4.

\section{Modified Binder with Treated WCO}

The XRD graph pattern for modified binder with treated WCO is depicted in Fig. 5. Based on the graph, the flat pattern graph without a peak was observed in this sample, which was similar with the control and modified binders with untreated WCO. It was noticed that only one noticeable peak was recorded at $18^{\circ} 2 \theta$ with $d=4.73$ for modified binder incorporating treated WCO. Basically, the ' $d$ ' value represented the width of the peak which indicated the crystallite size. The highest peak broadening was recorded by treated WCO in which it indicated a smaller crystallite size as compared to the control binder. The presence of a sharp peak pattern in the graph indicated that the crystalline phase or crystallinity existed in the sample. Meanwhile, the quite 'flat' and 'broad' like pattern with the absence of peak implied the amorphous structure due to the chemical atomic arrangement in the material. The crystalline structure depicted the ions, molecule or atom inside the material was arranged in periodic array while the amorphous structure indicated the irregular atomic arrangement.

The periodic array arrangement in the atom was able to diffract the X-ray which produced the diffraction pattern and vice versa. The diffraction pattern variation generated the peak in graph. Based on the graph pattern in XRD test, the control and modified binders possessed the amorphous structure since the non-existent of peak was recorded. It can be depicted that the molecule in the material was not arranged in periodic array, thus the light was not diffracted which in turn produced the graph with the absence of peak. Despite the only one peak observed for each material, it was represented as a minority peak and the non-peak exhibited more dominance which was recognised as an amorphous structure.

In addition, the flat trend of the XRD graph for modified binder indicated that the untreated and treated WCO were uniformly dispersed and homogenously mixed with the binder. The graph pattern obtained in this study was similar with the findings from Wan Azahar et al. [21] which concluded that the modifier was well dispersed and uniformly distributed in the mixes.

Another interpretation indicated that, the WCO and binder were well blended and achieved full homogenisation between these materials during the mixing process for modified binder production. The addition of WCO molecule into the binder molecule caused the atomic arrangement not to be in the long range order in the periodic array. This arrangement cannot diffract the $\mathrm{x}$-ray, thus did not produce the diffraction pattern. The absence of diffraction pattern will not produce the peak in graph. In this study, it was noticed that the graph was tabulated with broad scattering peaks without the notable sharp peaks. In summary, it had proven that a well-blended and homogeneous solution was produced in the modified binder with untreated and treated WCO. 


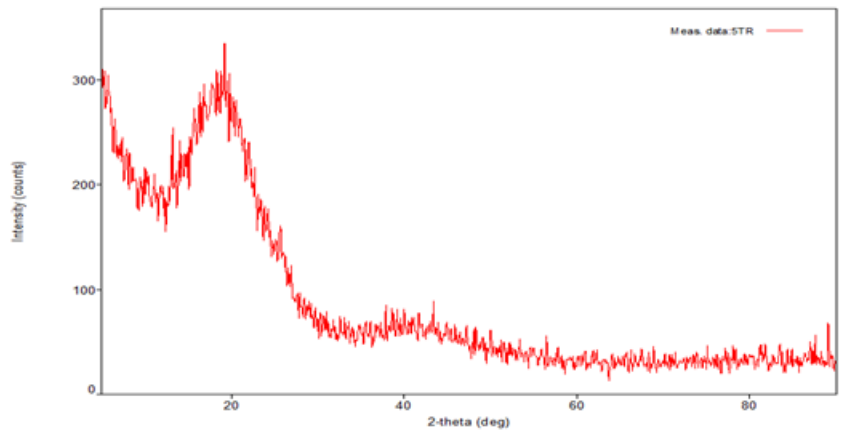

Fig. 5.

\section{CONCLUSION}

From control binder it can be seen that the notable consistency of graph pattern, without the presence of large peak where the modified binder with untreated WCO shows that minor component crystalline structure. On the other hand, the highest peak broadening was recorded by treated WCO indicated a smaller crystallite size as compared to the other sample. It can be said that the XRD pattern graph proved that the untreated and treated WCO were homogeneously mixed in the modified binder.

The potential of treated WCO proved an outstanding and promising modifier for pavement materials with better rheological and mechanical performance as compared to the control binder and untreated WCO.

\section{ACKNOWLEDGMENT}

The support provided by the Malaysian Ministry of Higher Education and Universiti Malaysia Pahang in the form of a research grant (RDU/UMP) vote number RDU1803160 for this study is highly appreciated.

\section{REFERENCES}

1. J. Cvengroš and Z. Cvengrošová. (2004). Used Frying Oils and Fats and Their Utilization in the Production of Methyl Esters of Higher Fatty Acids. Biomass and Bioenergy, 27(2), 173-181.

2. A. B. Chhetri, K. C. Watts and M. R. Islam. (2008). Waste Cooking Oil as an Alternate Feedstock for Biodiesel Production. Energies, 1(1), 3-18.

3. Z. Yaakob, M. Mohammad, M. Alherbawi, Z. Alam and K. Sopian. (2013). Overview of the Production of Biodiesel from Waste Cooking Oil. Renewable and Sustainable Energy Reviews, 18, 184-193.

4. L. S. Kheang, C. Y. May, C. S. Foon and M. A. Ngan. (2006). Recovery and Conversion of Palm Olein-Derived Used Frying Oil to Methyl Esters for Biodiesel. Journal of Oil Palm Research, 18, 247-252.

5. I. Kabir, M. R. Yacob and A.Radam. (2014). Households' Awareness, Attitudes and Practices Regarding Waste Cooking Oil Recycling in Petaling, Malaysia. IOSR-Journal of Environmental Science, Toxicology and Food Technology, 8(10), 45-51.

6. Y. Chen, B. Xiao, J. Chang, Y. Fu, P. Lv and X. Wang. (2009) Synthesis of Biodiesel from Waste Cooking Oil using Immobilized Lipase in Fixed Bed Reactor. Energy Conversion and Management, 50(3), 668-673.

7. P. D. Patil, V. G. Gude, H. K. Reddy, T. Muppaneni and S. Deng. (2012). Biodiesel Production from Waste Cooking Oil using Sulfuric Acid and Microwave Irradiation Processes. Journal of Environmental Protection, 3, 107-113.

8. H. Asli, and M. R. Karim, (2011). Implementation of Waste Cooking Oil as RAP Rejuvenator. Journal of the Eastern Asia Society for Transportation Studies, 9, 1336-1350.

9. M. Zargar, E. Ahmadinia, H. Asli and M. R. Karim. (2012). Investigation of the Possibility of Using Waste Cooking Oil as a Rejuvenating Agent for Aged Bitumen. Journal of Hazardous Materials, 233-234, 254-258.
10. H. Asli, E. Ahmadinia, M. Zargar and M. R. Karim. (2012). Investigation on Physical Properties of Waste Cooking Oil Rejuvenated Bitumen Binder. Construction and Building Materials, 37, 398-405.

11. M. Zaumanis, R. B. Mallick and R. Frank. (2013). Use of Rejuvenators for Production of Sustainable High Content RAP Hot Mix Asphalt. The XXVIII International Baltic Road Conference. August 2013. Vilnius, Lithuania, 1-10.

12. M. Chen, B. Leng, S. Wu and Y. Sang. (2014a). Physical, Chemical and Rheological Properties of Waste Edible Vegetable Oil Rejuvenated Asphalt Binders. Construction and Building Materials, 66, 286-298.

13. L. Binbin, C. Meizhu and W. Shaopeng. (2014). Effect of Waste Edible Vegetable Oil on High Temperature Properties of Different Aged Asphalts. Key Engineering Material, 599, 135-140.

14. M. Chen, F. Xiao, B. Putman, B. Leng and S. Wu. (2014b). High Temperature Properties of Rejuvenating Recovered Binder with Rejuvenator, Waste Cooking and Cotton Seed Oils. Construction and Building Materials, 59, 10-16.

15. H. Wen, S. Bhusal and B. Wen. (2013). Laboratory Evaluation of Waste Cooking Oil-Based Bioasphalt as an Alternative Binder for Hot Mix Asphalt. Journal of Materials in Civil Engineering, 25(10), 1432-1437.

16. R. Maharaj, V. R. Harry and N. Mohamed. (2015). Rutting and Fatigue Cracking Resistance of Waste Cooking Oil Modified Trinidad Asphaltic Materials. The Scientific World Journal, DOI $10.1155 / 2015 / 385013$

17. Z. Sun, J. Yi, Y. Huang, D. Feng and C. Guo. (2016). Properties of Asphalt Binder Modified by Bio-Oil Derived from Waste Cooking Oil. Construction and Building Materials, 102, 496-504

18. P. Teymourpour, S. Sillamäe and H. U. Bahia. (2015). Impacts of Lubricating Oils on Rheology and Chemical Compatibility of Asphalt Binders. Road Materials and Pavement Design, 16, 50-74

19. N. M. Katamine. (2000). Physical and Mechanical Properties of Bituminous Mixtures Containing Oil Shales. Journal of Transportation Engineering-ASCE, 126(2), 178-184.

20. M. N. Borhan, F. Suja, A. Ismail and R. A. O. K. Rahmat. (2009). The Effects of Used Cylinder Oil on Asphalt Mixes. European Journal of Scientific Research, 28(3), 398-411.

21. W. N. A. Wan Azahar, R. Putra Jaya, M. R. Hainin, M. Bujang and N Ngadi. (2017). Mechanical performance of asphaltic concrete incorporating untreated and treated waste cooking oil. Construction and Building Materials 150, 653-663. 